\title{
La privatización del espacio público: los fraccionamientos y privadas "autocerrados" de clase media alta en la zona oriente de Morelia, México
}

\author{
Claudia Rodríguez Espinosal; Erika Elizabeth Pérez Múzquiz"
}

\section{RESUMO}

A partir de la situación de inseguridad que prevalece en gran parte de México, y en especial en el estado de Michoacán, la búsqueda de entornos más "seguros" ha llevado a la generación de un fenómeno cada vez más común en la zona oriente de Morelia: la creación de fraccionamientos cerrados por parte de los habitantes de ciertas calles o zonas residenciales. Este fenómeno de privatización del espacio público y la autosegregación ha modificado por tanto la funcionalidad de la zona oriente de la ciudad y por tanto, el contexto inmediato de estas viviendas. En este trabajo, se plantea el estudio de dos casos: calles cerradas perpendiculares sobre la Avenida Solidaridad y sobre la Avenida Camelinas y un fraccionamiento en la colonia Ocolusen. La metodología empleada parte del análisis de cuatro casos análogos localizados en diferentes zonas de México, revisión de teorías y del diseño de instrumentos específicos (cuestionarios y entrevistas) que fueron aplicados a una muestra representativa y confrontada con información obtenida en INEGI y medios electrónicos. Los resultados obtenidos, muestran primero que el origen de estos fraccionamientos autocerrados surge del miedo, de la necesidad subjetiva de seguridad, y a pesar de su autosegregación, aún no se sienten completamente seguros dentro de sus cotos, aumentando su percepción del miedo.

Palabras-clave: autosegregación; fraccionamientos cerrados; imaginarios del miedo; inseguridad urbana subjetiva

\begin{abstract}
From the insecurity that prevails in Mexico, especially in the state of Michoacan, the search for more "safe" environment has led to the creation of an increasingly common phenomenon in the eastern part of Morelia: the creation of gated communities by the inhabitants of certain streets or residential areas. This phenomenon of privatization of public space and the self-segregation has changed therefore the functionality of the eastern part of the city and therefore the immediate context of these homes. Perpendicular streets closed on Avenida Solidaridad and the Avenida Camelinas and fractionation in the colony Ocolusen: In this work, the study of two cases arises. The methodology of the analysis of four similar cases located in different areas of Mexico, revision of theories and design of specific instruments (questionnaires and interviews) that were applied to a representative sample and confronted with information obtained from INEGI and electronic media. The results show first that the origin of these subdivisions self-closed stems from fear, of subjective need for security, and despite his self-segregation, not yet feel completely safe within their boundaries, increasing their perception of fear.
\end{abstract}

Keywords: self-segregation; closed subdivisions; imaginary fear; subjective urban insecurity 


\section{INTRODUCCION}

La sociedade mexicana se ha visto afectada por vários factores que han generado una crisis de seguridad. En primera instancia el tráfico de drogas que ha desembocado en balaceras, secuestros, extorsiones entre otros, ya que varias regiones de México (como Sonora en el norte del país y la Tierra Caliente de Michoacán, cuya capital es la zona de este análisis) son productores y exportadores de estupefacientes. La falta de oportunidades en la obtención de trabajos formales, también ha influido en el aumento de robos y extorsiones, grupos delictivos cobran derecho de piso a establecimientos pequeños y en genral, las guerras entre carteles por dominio de plazas se han desatado en los últimos 5 o 6 años en varias regiones del país. Como ejemplo, el estado de Michoacán en el cual se inserta el objeto de esta investigación, basa su economía en ingresos provenientes del turismo, las remesas (dinero enviado por trabajadores ilegales en Estados Unidos de América a usu familiares en México) y el narcotráfico.

Esta crisis nacional en el territorio mexicano, ha desatado una ola de delitos que se ha reflejado en un gran incremento de inseguridad y por lo tanto, de nuevos imaginarios del miedo. Ello ha desembocado en nuevos procesos urbanos, cada vez más complejos, pero que como siempre, son el reflejo en la ciudad de las sociedades que la habitan, y la transforman, acorde a los constantes cambios que las dinámicas sociales crean (Mejía y Lamy, 2014, p.221).

Dentro de estas dinámicas, un factor de impacto negativo en la calidad de vida son los procesos de degradación ambiental y relacional, acorde a lo citado por Bartolini (2010).

En este contexto, tenemos nuevos escenarios urbanos, que responden a estos imaginarios y a la búsqueda por parte del mercado inmobiliario de ofertar "soluciones" a esta ingente necesidad de seguridad que los actuales habitantes urbanos buscan. La cada vez más abundante oferta de cotos o fraccionamientos cerrados, inundan los medio publicitarios, ofertando "seguridad 24 horas al día" o 
"vigilancia continua", "accesos controlados", "cámaras de seguridad en todas las áreas", y un largo etcétera que busca calmar el sentimiento de indefensión ante la ola de violencia que se vive en muchas regiones de México.

Esta situación, es vista también como una autosegregación, una búsqueda de aislarse del "otro" que puede atacarnos, y que por supuesto es también resultado de esta cultura del miedo y la inseguridad que prevalece en todos los estratos socioeconómicos: tanto la clase alta, como la media y la baja, tiene temor de ser robados o violentados en cualquier momento. Sobre todo, en el espacio en el que todo ser humano se siente más vulnerable: el hogar. Nuevas formas de vida surgen entonces, con nuevas reglas para la socialización dentro de estos cotos, y por tanto, la creación de nuevas identidades urbanas reducidas a estos espacios privados (De la Torre, 2014, p.35).

Por ello, se ha podido observar en la literatura sobre el tema de estudio, varios trabajos académicos, con enfoques complementarios, que tratan de entender estos complejos procesos sociales que tienen su reflejo en lo urbano. Los enfoques se seleccionaron por los siguientes aspectos en que hacen énfasis y que brindan sustento a la propuesta de este trabajo: la privatización del espacio público por ejemplo (Rosas Molina, 2010); el planteamiento del modelo urbano insustentable generado por las urbanizaciones cerradas (Lara Navarrete, 2010); la creación de fortificaciones habitacionales a partir del imaginario que usa la violencia dominante a violencia dominadora (López Levi, 2011); así como el de la inseguridad urbana subjetiva en fraccionamientos cerrados (Galaviz Mosqueda y Valladares Anguiano, 2014).

A partir de la revisión de estos enfoques, se propone retomar aquel que permita analizar el caso específico de este estudio, que difiere de los trabajos revisados en un aspecto fundamental: la creación de un fraccionamiento privado por parte de los mismos habitantes a través de construcción de bardas y casetas de control de acceso, y la privatización de varias calles cerradas mediante la colocación 
de rejas con operación a control remoto por parte de los mismos residentes de estas calles, todos ubicados en la zona oriente de la ciudad de Morelia, Michoacán.

De este modo, este documento presenta en una primera parte, la revisión de los estudios realizados en cuatro regiones diferentes de México: Nogales en Sonora, Mérida en Yucatán, la Ciudad de México y la conurbación Colima-Villa de Álvarez en Colima. Posteriormente se define la metodología empleada para el caso de estudio, y finalmente se presentan los resultados obtenidos.

\section{LOS ENFOQUES NACIONALES}

El primer trabajo analizado, localizado su objeto de estudio en la ciudad fronteriza de Nogales en el estado de Sonora, al norte de la República Mexicana, forma parte de una serie de trabajos realizados por el grupo de investigación perteneciente al Colegio de Sonora. En este caso, Rosas Molina analiza estos fraccionamientos cerrados, bajo la premisa de que "la consecuencia socio-espacial más importante del surgimiento de los fraccionamientos cerrados es la privatización del espacio antes público, ahora exclusivo de los residentes de estos enclaves urbanos; por ende, sus efectos sociales y urbanos son la segregación-autosegregación (exclusión social), así como la fragmentación espacial y el rompimiento con la trama urbana; de esta manera, los fraccionamientos cerrados conforman células independientes con reglamentos internos propios, que los vuelven autogobernables al administrarse por ellos mismos" (Rosas Molina, 2010, p.127-128).

La ciudad de Nogales, presenta características únicas, al ser fronteriza y contar con una población flotante y migrante que depende en mucho de la industria maquiladora, y que por tanto, tiene diferencias socioeconómicas muy marcadas, además de haberse desarrollado sin un plan de desarrollo o de crecimiento urbano establecido. A partir de estas condicionantes, Rosas Molina busca el origen de la introducción del modelo de cerramiento cerrado, incluyendo elementos como la 
especulación inmobiliaria, el acaparamiento de terrenos ejidales por algunos especuladores, la inversión en infraestructuras en algunas zonas habitacionales y el abandono de otras sobre todo periféricas, y principalmente la influencia del mercado inmobiliario.

Aunado a este modelo, analiza el papel que el espacio público ha tenido en la ciudad de Nogales, y su progresiva privatización, mediante la exclusión social asociada a cuestiones de clase y de inseguridad o temor. "Hay un temor al espacio público, que ha sido ocupado por 'los otros', la 'otredad' de la que se habla con varios nombres; las clases peligrosas de la sociedad: inmigrantes, pobres o marginados, los que tiene otro fenotipo, homosexuales, sexoservidoras, discapacitados o ancianos, entre muchos otros". (Rosas Molina, 2010, p.136)

El gobierno ha favorecido esta segregación social, creando espacios "públicos" de calidad, pero casi exclusivamente en zonas residenciales de clase alta, o dentro de megaproyectos relacionados con recreación para estas clases adineradas. "Con lo anterior, la exclusión social y la fragmentación socioespacial es más evidente en las ciudades donde el modelo de fraccionamiento cerrado está delineando esta nueva forma de intervención urbana". (Rosas Molina, 2010, p.139)

Otras formas importantes de exclusión en los espacios públicos, son las que el autor reconoce como barreras arquitectónicas y barreras sociales, que relaciona con la accesibilidad. Esta idea la relaciona con el posterior descuido y abandono de los espacios públicos, siendo reemplazadas plazas consideradas como "peligrosas" por centros comerciales que han venido a sustituir al espacio público, pero por supuesto con acceso controlado y discriminatorio, mediante las llamadas barreras sociales y arquitectónicas (cámaras de seguridad, alarmas, seguridad privada, cobro de estacionamiento, paraderos de servicio público alejados, etc.) Esto lleva a la creación de ciudades fragmentadas, con casi nula interacción social. La casi total carencia de espacios públicos en Nogales, ha llevado a que “...la gente cruza al otro lado de la frontera en busca de alimentos, ropa...y de espacio público". (Rosas Molina, 2010, p.151) 
El segundo enfoque a analizar en este documento, es el presentado en la ciudad de Mérida, en el estado de Yucatán en el sur de la república Mexicana. Lara Navarrete (2010), presenta un estudio del impacto negativo que la proliferación de fraccionamientos cerrados en las últimas décadas del siglo XX y lo que va del siglo XXI, ha tenido en los aspectos ambiental, social y económico-administrativo.

Esta propagación de las Ilamadas Unidades Cerradas, acorde a Lara Navarrete, es causada por los antecedentes socioeconómicos y culturales de la sociedad de Mérida; estas unidades son un producto muy atractivo en el mercado inmobiliario gracias al interacción de los tres agentes principales: habitantes, constructores y administraciones locales; además no existe un marco normativo o jurídico que regule a estas unidades cerradas de manera específica, para finalmente hacer referencia a los procesos globalizantes (tecnológicos y económicos) que favorecen su proliferación, sobre todo a partir de los ejes centrales de la desregularización y privatización de las tareas estatales, su comercialización como parte la cultura global que marca que las élites sociales deben vivir en cotos cerrados, y el aumento de la percepción de inseguridad a través de medios de comunicación masiva y el fenómeno de la inmigración masiva. (Lara Navarrete, 2010, p.342-343).

A partir entonces de un estudio de larga duración (más de tres años), Lara Navarrete identifica los siguientes impactos. En el aspecto ambiente construido, se generó el aislamiento o disminución de la libre accesibilidad; largas bardas cerradas que se traducen en la fragmentación físico-perceptible del medio construido; y el aumento no programado de la demanda de servicios de infraestructura, servicios urbanos y áreas para edificación.

En el aspecto social, Lara Navarrete identifica la disminución del uso de espacios urbanos abiertos; transformaciones en las formas de habitar tradicionales; disminución de la diversidad demográfica en los cotos cerrados y por tanto la fragmentación social definida en cinco categorías: nivel socioeconómico, escolaridad, religión, procedencia y tiempo de habitar el lugar. 
Finalmente, el impacto económico y administrativo se muestra en que al ser grandes manzanas cerradas de grandes dimensiones, genera que la sociedad deba realizar grandes recorridos a su exterior; al no tener un marco legislativo y normativo se crean importantes lagunas en la gestión urbana y "la tendencia al reemplazo de la administración pública" (Lara Navarrete, 2010, p.352).

El tercer estudio a ser analizado, se focaliza en los fraccionamientos cerrados de la Ciudad de México, y el enfoque que desarrolla es el de la violencia, la segregación espacial y los imaginarios urbanos, "Para responder, interpretar, rechazar o asimilar a la violencia que parece dominar la esfera nacional, la gente construye imaginarios sociales, que después serán la base de sus prácticas y representaciones en torno al fenómeno" (López Levi, 2011, p.64).

La violencia y la criminalidad han sido y siguen siendo medidas en México por órganos gubernamentales que emiten "cifras oficiales", en los medios informativos, en empresas encuestadoras, etc. Para 2010, el Instituto Nacional de Estadística, Geografía e Informática (INEGI) reportaba que el $65 \%$ de la población se sentía insegura a nivel nacional, para este año 2015, esta cifra es manejada en $44.1 \%$ (INEGI, 2015).

López Levi (2011) maneja la idea de que el miedo y la inseguridad se reflejan en el paisaje urbano, con cotos cerrados, calles erradas, edificios tipo bunker, espectaculares ofreciendo recompensas o campañas políticas ofreciendo acabar con este fenómeno, rejas, cámaras de vigilancia, cercas eléctricas, etc. La Figura urbana se ha modificado a partir de estos imaginarios del miedo.

Retomando el primer punto, menciona el origen de estos fraccionamientos privados desde el siglo XIX, aunque su expansión se dio a partir de finales del siglo pasado y lo que va del actual. Señala que es un modelo tan exitoso, que se ha diseminado por toda la República Mexicana, abarcando no solo las élites sociales, sino también la vivienda de interés social como los mega conjuntos habitacionales creados por empresas como Casas Geo, Ara, URBI, Herso, etc. Este éxito, se basa principalmente 
en una respuesta al imaginario del miedo, generada por la violencia dominante, definida como la percibida por los habitantes por López Levi (2011, p.68).

Analizando diversas fuentes, principalmente en publicaciones periódicas, López Levi señala que a pesar de la promesa de seguridad vendida por el mercado inmobiliario, la realidad es que los robos y violencia llegan adentro de estos fraccionamientos fortificados, no solo en los de clase media o baja, sino también en los de las élites sociales. Sin embargo, a pesar de ello, el vivir dentro de estos cotos cerrados si baja la percepción del miedo.

Finalmente, la autora concluye que “...la violencia dominante en México, que produce el miedo, que lleva a la gente a buscar seguridad en los fraccionamientos cerrados, que los justifica como un espacio deseable, se convierte en un instrumento de dominación, ya que el espacio resultante se opone a ciertos valores de la democracia y libertad de los que los ciudadanos se sienten partícipes" (López Levi, 2011, p.76). En conclusión: el miedo y la violencia venden.

El cuarto caso de estudio, se localiza en la zona conurbada de Colima y Villa de Álvarez en el estado de Colima, y se enfoca en la inseguridad urbana subjetiva de los fraccionamientos cerrados de clase alta. Esta investigación parte de la idea de que factores tan subjetivos como la percepción de riesgo, imaginarios del miedo y sentimientos de inseguridad, transforman las dinámicas urbanas, las prácticas sociales y la vida cotidiana de los habitantes de estos fraccionamientos cerrados. Acorde a Galaviz y Valladares (2014)"...para comprender las lógicas sociales que forman parte de la reproducción de este modelo es indispensable una mirada hacia los efectos que los aspectos negativos detectados, en particular, los relativos a la inseguridad urbana, están generando en las estructuras socio-urbanas" (Galaviz y Valladares, 2014, p.110).

Entonces, se busca responder a la pregunta de cómo los sentimientos (subjetivos) de miedo e inseguridad, se relacionan directamente con las condiciones de encerramiento y aislamiento de los fraccionamientos cerrados, en una autosegregación protectora ante los altos índices de violencia y la inseguridad 
generalizada en México, pero en particular en el caso de estudio de la conurbación Colima-Villa de Álvarez.

A partir de este planteamiento, los autores desarrollan la metodología siguiente: "bajo un método descriptivo-correlacional, a través de una estrategia no experimental del tipo cuali-cuantitativo, mediante muestreo probabilístico por medio de cuestionarios y desarrollo de dinámicas de grupo de opinión, que nos permitiera obtener datos empíricos sobre las relaciones entre la privatización del espacio, entendida como un estilo de vida globalizado, expresado territorialmente a través de los fraccionamientos cerrados [...]que genera condiciones de encerramiento y aislamiento socio-urbano, con la percepción de riesgo y la consolidación de los imaginarios del miedo" (Galaviz y Valladares, 2014, p.110).

A través de la aplicación de herramientas generadas para este método de investigación, y haciendo un contraste entre población interna (habitantes de los fraccionamientos cerrados de clase media alta) y población externa (habitantes de fraccionamientos abiertos de clase media alta, a modo de población testigo), se pudo llegar a varias conclusiones.

En general, los fraccionamientos cerrados, en lugar de hacer sentir más seguros a sus habitantes, los hace sentir con más miedo, incrementando sus sentimientos de inseguridad y vulnerabilidad. Aunque ya cuentan con medios de seguridad como cámaras de vigilancia, cercas, control de acceso, un alto porcentaje señalan que aún deben aumentar las medidas de seguridad. En general, al aumentar el aislamiento y la autosegregación en estos fraccionamientos cerrados, más se incrementan los sentimientos de inseguridad generados por los imaginarios del miedo Juárez Martínez, 2006, p.45).

\section{EL CASO DE MORELIA}

En el año de 1999, el índice de criminalidad en Morelia aumentó acorde a la percepción de la sociedad, como quedó registrado en los medios informativos locales 
y organismos estadísticos nacionales (ICESI, 2015). Como una respuesta directa, se dio uno de los primeros casos en Morelia de obstruir varias calles con bardas para crear un coto cerrado, dejando una sola entrada de acceso controlado a través de una caseta de vigilancia (ver Figura 1).

Figura 1: Mezquite esquina con Ocolusen, pertenece al AGEB 160530001963

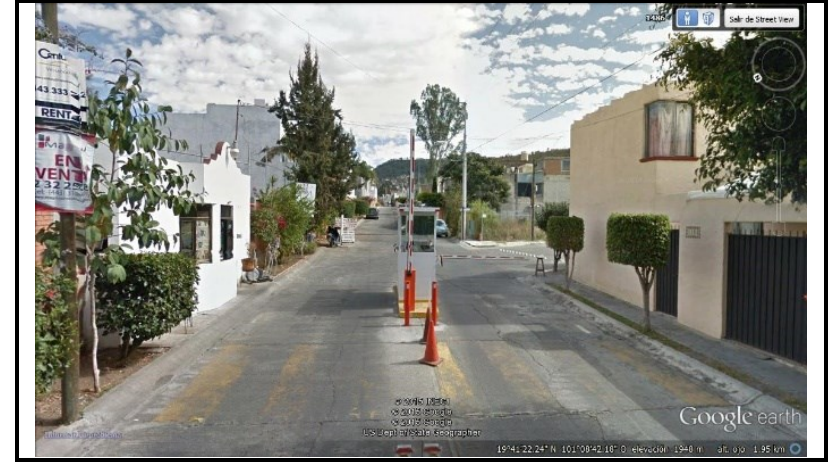

Fuente: Google Street [10/10/2015]

Este fraccionamiento se ha ido consolidando a lo largo de los años, generando un esquema que ha sido repetido en varias ocasiones y en diversas zonas de la ciudad de Morelia. Como puede apreciarse, es notorio el deseo de búsqueda de seguridad por parte de los habitantes de esta zona, resultado aparentemente del incremento de la violencia y robos a casa habitación en esta zona. La persona que inició con esta idea, reside en la calle Mezquite, y es un prominente empresario y político de la capital michoacana.

Revisó los planos de la zona y comenzó con una campaña entre vecinos para convencerlos y que se sumaran a su proyecto de crear un fraccionamiento “autocerrado". La labor prosperó y a través de su propia empresa constructora, logró cerrar las calles necesarias con bardas hacia el interior, como puede observarse en la Figura 2.

Figura 2: Localización del primer caso de estudio 


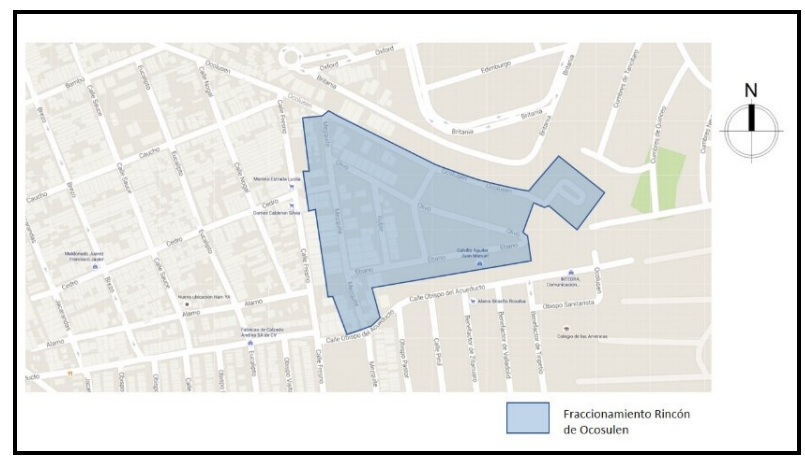

Fuente Google Earth [15/12/2015]

La cantidad de lotes participantes es de 80 viviendas, y además se generaron áreas verdes para disfrute de los residentes, inclusive hay un espacio para reuniones sociales que cualquiera de ellos puede utilizar. También hay una zona de juegos para los niños del fraccionamiento. Todos estos espacios generan gastos que son cubiertos por las cuotas mensuales que los residentes aportan.

Posterior a estos procesos, el gobierno municipal intentó controlar estos hechos, a través de modificaciones al plan de Desarrollo Urbano de Morelia, sobre todo en los documentos del 2008 y posteriores. Sin embargo, este proceso ha aumentado en vez de disminuir, como puede apreciarse en esta nota periodística:

Los conflictos por cierres de calles ante la inseguridad en la capital michoacana no sólo proliferan, sino que además se vuelven más conflictivos en algunos puntos de la ciudad. El pretexto de evadir a la delincuencia continúa como el argumento para evitar la circulación por vialidades de la capital michoacana, y en su mayoría lo hacen sin los debidos permisos y sin consenso de los habitantes de la zona. (Castro, 2015)

Otro caso muy notorio y que se tomó como el segundo caso de estudio, corresponde a una serie de calles privadas que se encuentran en su parte cerrada con un parque infantil Ilamado "Morelia 150" y por su parte abierta con dos avenidas principales de gran afluencia vehicular: Av. Camelinas y Av. Solidaridad (ver Figura 3). 
Figura 3: Localización del segundo caso de estudio

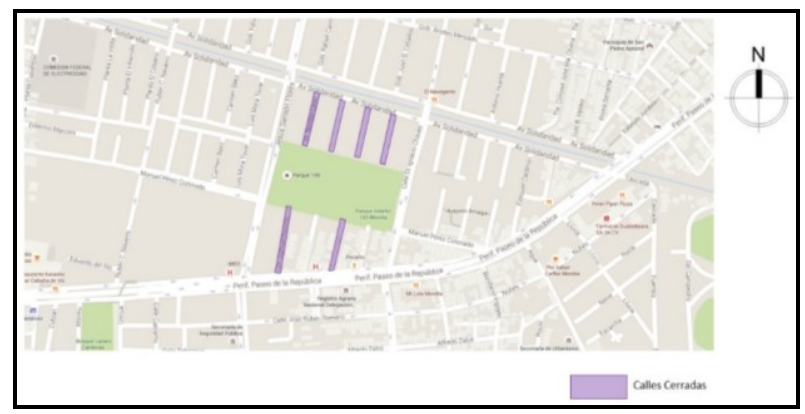

Fuente Google Earth [15/12/2015]

Sobre la Avenida Camelinas, y entre estas calles, se han ubicado varios bares o "antros" que venden bebidas alcohólicas y que tienen música a muy alto volumen hasta las 2 o 3 de la mafrugada. Algunos de los usuarios de estos bares, acostumbraban a utilizar las puertas de las viviendas como sanitarios públicos, lo cual contribuyó a la decisión de los residentes de cerrar las calles.

Los residentes de estas seis calles cerradas, aprovechando por una parte la condición de tener un límite ya marcado, y por otra el que son relativamente pocas casas en cada calle, facilitó el proceso de cooperar para cerrar los accesos con rejas, algunas con control remoto (ver Figura 4), para intentar mejorar la seguridad de esta zona, cuyo índice de delincuencia aumentó cuando al demoler el antiguo Hospital Regional del Instituto Mexicano del Seguro Social ubicado en la AV, Héroes de Nocupétaro en agosto del año 2011 y antes de su reubicación en las nuevas instalaciones en la llamada "Ciudad Salud" ubicada en la zona oriente de Morelia, en la salida a Charo, fueron trasladados sus servicios médicos a la Clínica familiar 75, localizada a pocas cuadras del caso de estudio.

Figura 4: Avenida Solidaridad esquina con Dr. Nicolás León, pertenece al AGEB 1605300010594 


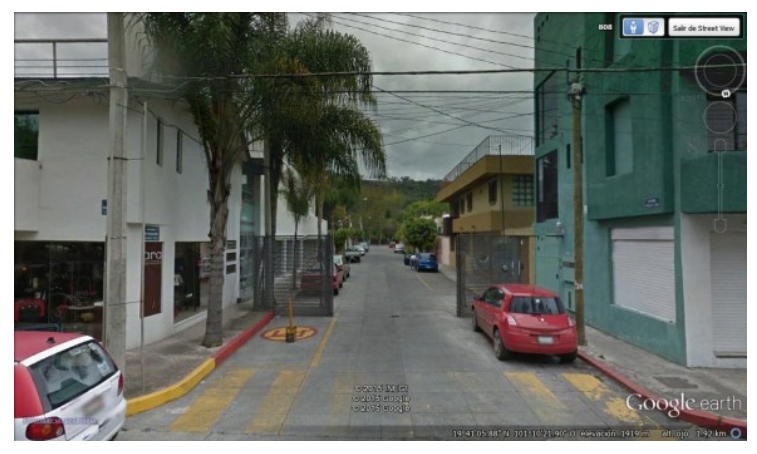

Fuente: Google Street [10/10/2015]

De un día para otro, los residentes de esta zona se enfrentaron a una sobresaturación vehicular, en que no solo los pacientes o familiares que acudían a este centro de salud tapaban sus cocheras, sino que el robo a casa habitación de incrementó exponencialmente junto con vandalismo a sus vehículos en caso de dejarlos estacionados frente a sus viviendas, generando una necesidad inmediata de seguridad y de control de acceso a estas calles. La organización de los residentes les permitió realizar estas acciones de forma rápida y expedita, reduciendo el número de robos a casa habitación y vandalismo en sus vehículos.

\section{METODOLOGÍA Y RESULTADOS}

Tomando algunos puntos de la estrategia metodológica desarrollada por Galaviz y Valladares (2014), y retomando sus instrumentos de medición, se realizaron cuestionarios específicos para ser aplicados en los objetos seleccionados para este estudio, utilizando un sistema de aplicación directa a los habitantes tanto del fraccionamiento como de las calles cerradas. Los aplicadores de encuestas (estudiantes de $9^{\circ}$ semestre de la Facultad de Arquitectura de la Universidad Michoacana de San Nicolás de Hidalgo y que prestan su servicio social dentro de los proyectos de investigación coordinados por las autoras).

El total de lotes habitados en el fraccinamiento cerrado es de 80 viviendas, de las cuales se aplicaron cuestionarios a 60 de ellas; mientras que las calles cerradas 
tienen un total de 50 lotes habitados, de los cuales se les aplicó a 50, lo cual se considera una muestra representativa de la población de los objetos de estudio, acorde a la metodología establecida por Hernández Sampieri (et.al., 2008).

Los resultados obtenidos son los siguientes:

Con respecto a la caracterización de los residentes del fraccionamiento autocerrado (ver Cuadro 1), se obtuvo una mayoría de personas del sexo femenino que respondieron las encuestas, con educación media a superior, originarios de Morelia y cuyos padres son morelianos también, y con más de 5 años de residir en el lugar de estudio. Esta información permite establecer un perfil socio económico de la muestra, ya que considerando que la información obtenida es de percepción, lo subjetivo puede equilibrarse al establecer que se trata de un grupo social de clase media alta. Por ejemplo, el hecho de que sean originarios de Morelia, generará una opinión más favorable a la ciudad que aquellos que llevan poco tiempo de residencia.

Cuadro 1: Caracterización de la población residente en el fraccionamiento autocerrado
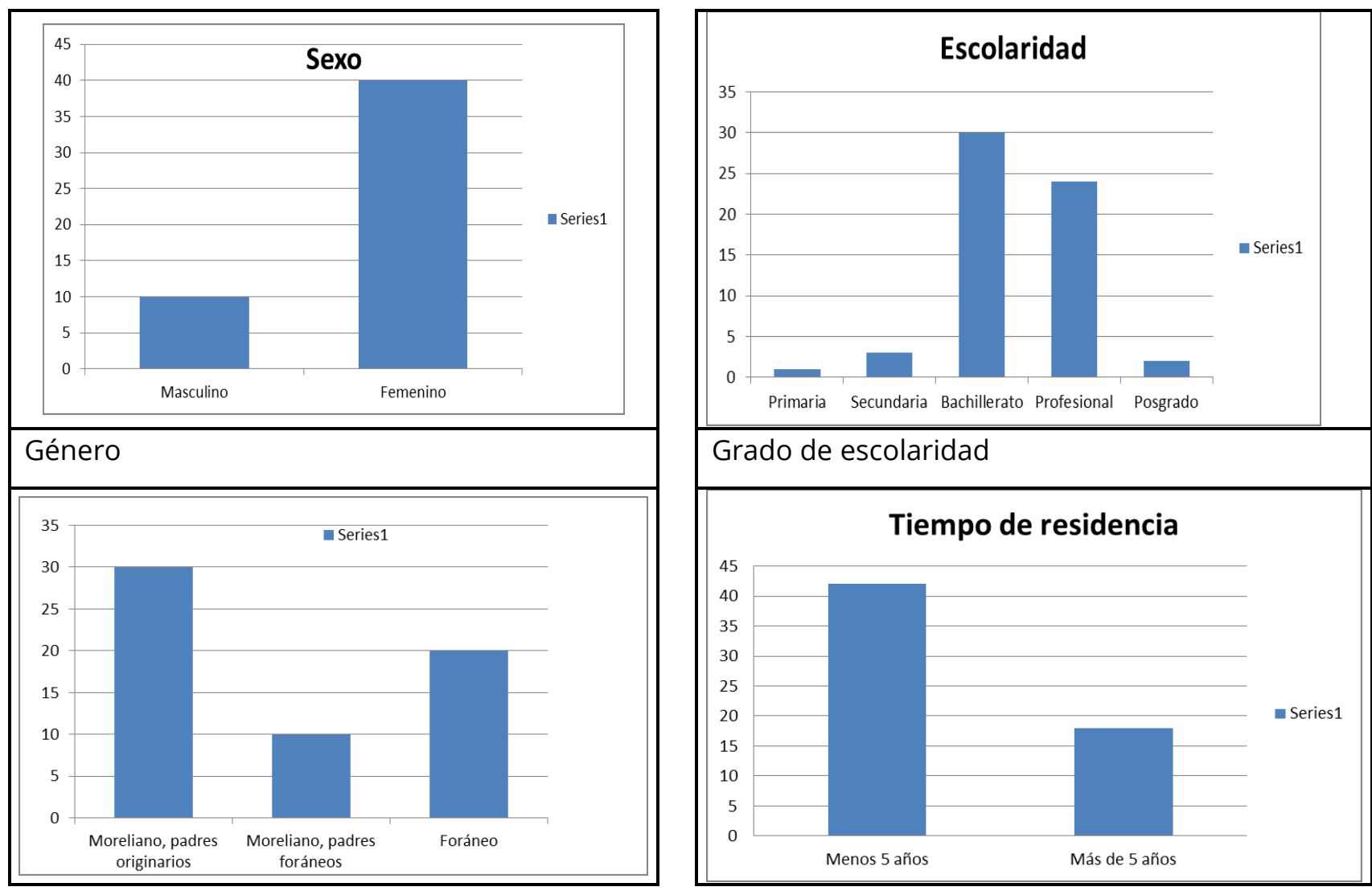
El segundo grupo de preguntas, fueron dirigidas a la percepción de los residentes en cuatro aspectos básicos, primero si han sido víctimas de delitos dentro de los límites del fraccionamiento en el que residen; su percepción en cuanto a la seguridad y protección que las condiciones de autocerramiento de su fraccionamiento les genera, y finalmente la calidad espacial de su lugar de residencia, teniendo los siguientes resultados (ver Cuadro 2) Se considera la escala de medición Muy Alta, Alta, Media, Baja y Ninguna que son categorías con la que los entrevistados pudieron relacionarse.

La mayor parte de los residentes nunca han sido víctimas de delitos dentro del coto cerrado, pero el $20 \%$ de los residentes han sufrido delitos tres o más veces en sus casas o en las calles que están ubicadas dentro los límites. La percepción de seguridad generada por cerrar estas calles y crear un coto, predomina de muy alta y alta, sin respuestas de baja percepción, lo cual puede interpretarse como que la mayoría de los residentes se sienten seguros dentro de su fraccionamiento. Sin embargo, el $60 \%$ de los encuestados, sienten que los medios de protección dentro de su coto les ofrecen una protección media, lo cual contradice lo anteriormente expuesto en apariencia, ya que al profundizar en el tema con varios encuestados, se manifestó un deseo de modernizar el sistema de vigilancia existente con cámaras. El otro factor cuestionado fue el de la calidad espacial, en que las respuestas apuntan a una satisfacción del ambiente construido en el cual residen.

Cuadro 2: Percepción de la población residente en el fraccionamiento autocerrado 

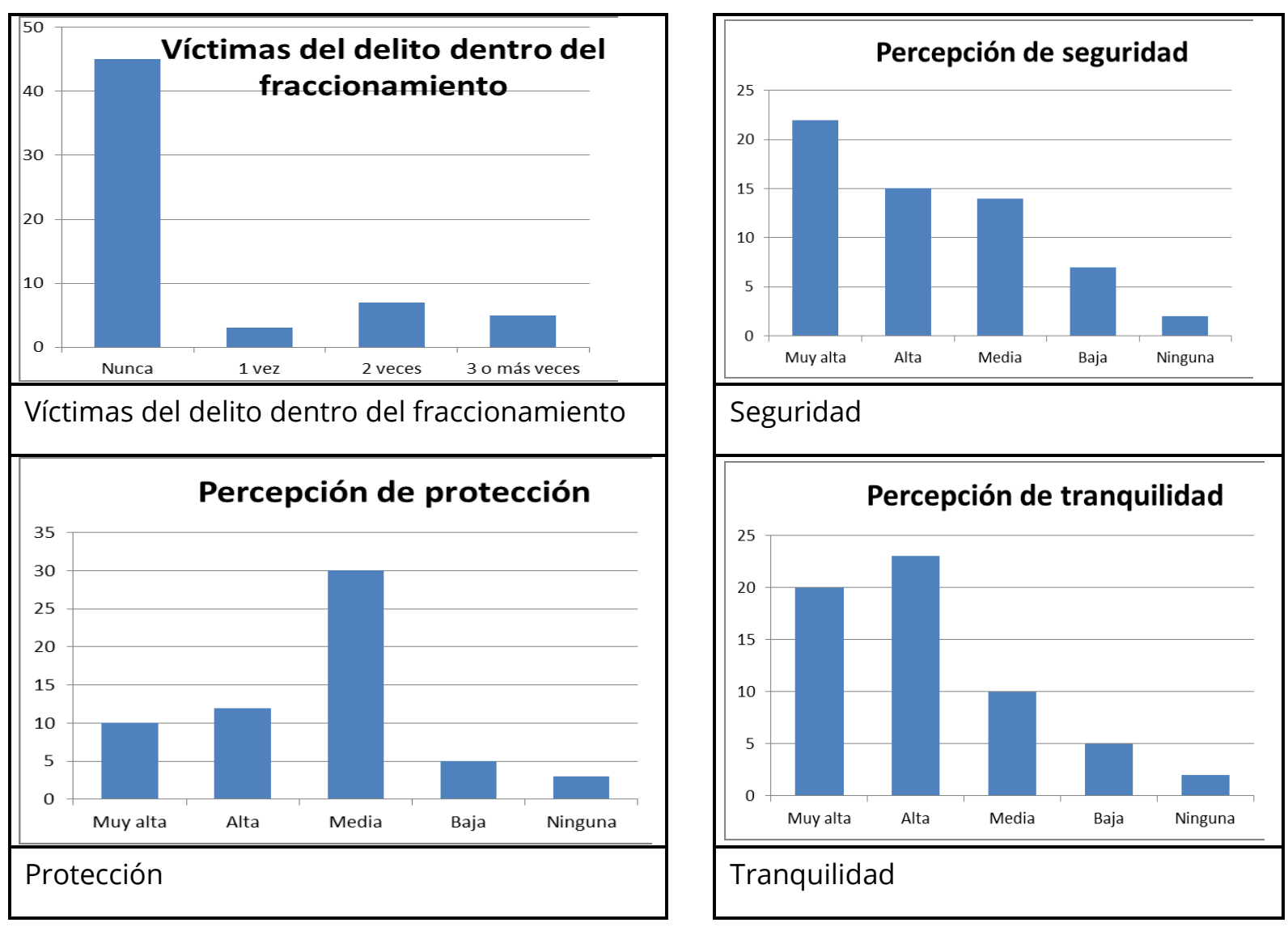

Finalmente, el tercer grupo de preguntas a ser presentado en este trabajo (ya que los cuestionarios y encuestas son más amplios cubriendo varias temáticas complementarias, pero por cuestiones de tamaño no serán abordados aquí) tienen que ver con los imaginarios del miedo, relacionando la percepción de seguridad de los habitantes encuestados en tres ambientes: vivienda, fraccionamiento, ciudad de Morelia. Los resultados obtenidos en la aplicación de encuestas a los habitantes del fraccionamiento autocerrado se reflejan en el Cuadro 3 a continuación.

Cuadro 3: Percepción de los imaginarios del miedo de la población residente en el fraccionamiento autocerrado 


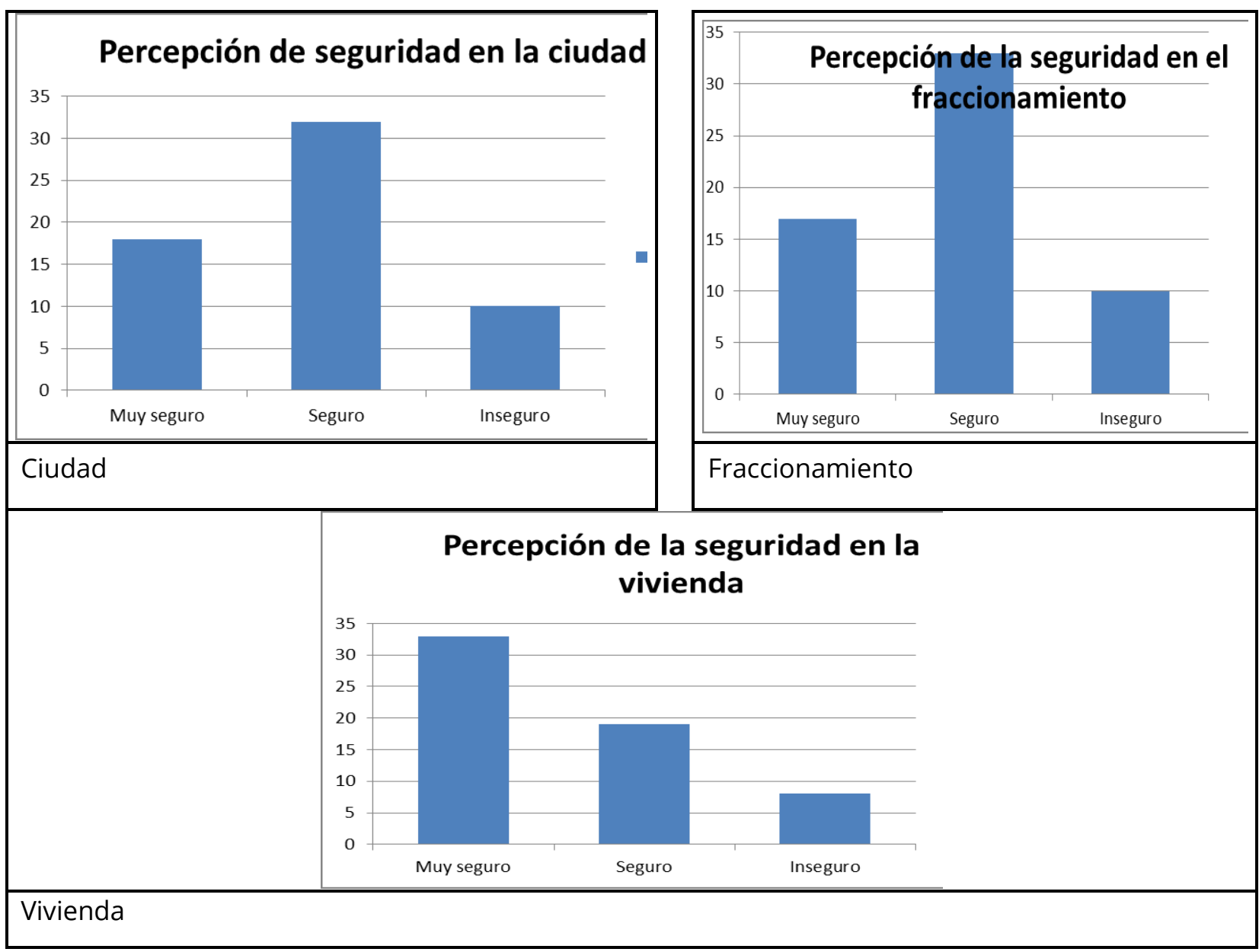

Como puede observarse, el miedo se percibe de manera muy fuerte en el contexto de la ciudad, disminuyendo dentro del fraccionamiento autocerrado y llegando a un $67 \%$ de seguridad alta dentro de las viviendas. Para completar estas encuestas, se realizaron levantamientos in situ, generando las siguientes gráficas (ver Cuadros 4 y 5$)$.

Cuadro 4: Levantamiento interior Fraccionamiento cerrado

\begin{tabular}{|c|c|c|c|c|c|c|c|}
\hline \multicolumn{8}{|c|}{ Vialidades Internas } \\
\hline \multicolumn{2}{|c|}{ Jerarquía } & \multicolumn{2}{|l|}{ Dimensiones } & \multicolumn{2}{|c|}{$\begin{array}{ll}\text { Tipo } & \text { de } \\
\text { pavimento } & \\
\end{array}$} & \multicolumn{2}{|l|}{ Calidad espacial } \\
\hline Primaria & 1 & $\begin{array}{ll}\text { Ancho } & \text { de } \\
\text { toda } & \text { la } \\
\text { sección } & \end{array}$ & $\begin{array}{l}11.40 \\
\mathrm{~m} .\end{array}$ & Terracería & & $\begin{array}{l}\text { Estado de } \\
\text { Conservación } \\
\text { predominante }\end{array}$ & Bueno \\
\hline Distribución & 5 & $\begin{array}{l}\text { Ancho de } \\
\text { la acera }\end{array}$ & $8.30 \mathrm{~m}$. & Empedrado & & $\begin{array}{l}\text { Arborización } \\
\text { para el peatón }\end{array}$ & Regular \\
\hline Local & 2 & \multirow{3}{*}{$\begin{array}{l}\text { Ancho de } \\
\text { la } \\
\text { banqueta }\end{array}$} & \multirow{3}{*}{$3.60 \mathrm{~m}}$. & Asfalto & & \multirow{3}{*}{$\begin{array}{l}\text { Alumbrado } \\
\text { público }\end{array}$} & \multirow{3}{*}{ Bueno } \\
\hline Peatonal & 1 & & & Concreto & $\square$ & & \\
\hline Otra & & & & Adoquín & & & \\
\hline
\end{tabular}


Este cuadro, refleja el nivel de acceso que ladrones o intrusos puedan tener al fraccionamiento. Varios residentes comentaron que cuando salieron de vacaciones, un camión de mudanza ingresó al fraccionamiento para realizar una supuesta mudanza, cuando en realidad vaciaron ese domicilio. Como se sospechó del personal de seguridad, se cambió de compañía y se instalaron más cámaras de vigilancia.

Aunque se buscó la posibilidad de tomar fotografías del interior del fraccionamiento, el personal de seguridad nos lo prohibió, pero amablemente bridaron su apoyo para hacer el registro de las vialidades internas, usando flexómetros para medirlas. Sin embargo, para la parte exterior se pudieron tomar imágenes de Google Earth (ver Figura 5) que complementaran lo observado directamente en el sitio.

Figura 5: Pirul esquina con Obispo del Acueducto, pertenece al AGEB 160530001963

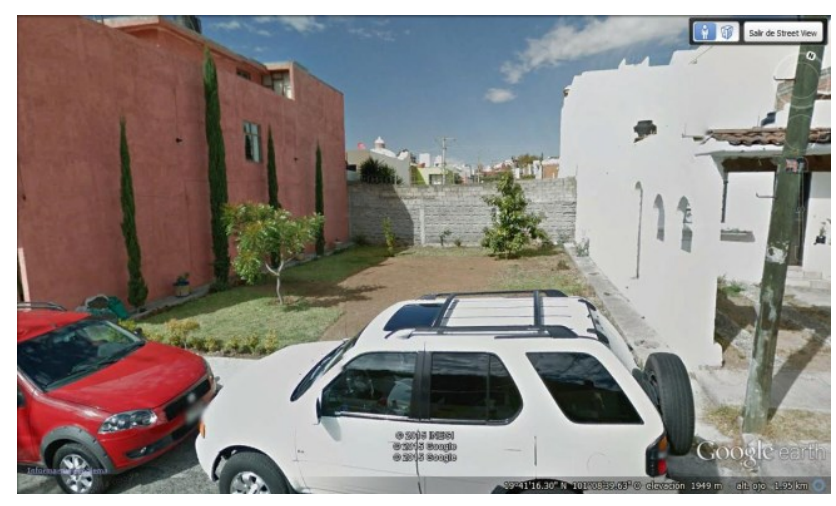

Fuente: Google Street [10/10/2015]

Por ejemplo se puede prestar atención la calle tapiada aprovechada por los vecinos exteriores al fraccionamiento como una pequeña plaza en la que en ocasiones hacen festejos o comidas, y cuya vegetación es cuidada por ellos mismos. En la Figura 6 puede verse otra de las bardas limítrofes del fraccionamiento, en este caso el espacio residual es utilizado por los vecinos externos al fraccionamiento como lugares extra de estacionamiento para sus vehículos, ya que la mayoría de las viviendas son de tamaño reducido. 
Figura 6: Ocolusen esquina con Obispo del Acueducto, pertenece al AGEB 160530001963

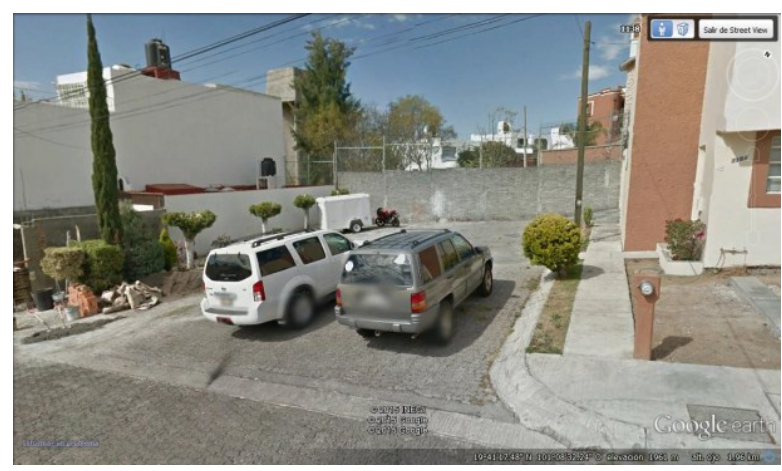

Fuente: Google Street [10/10/2015]

Esta información obtenida a través de la observación directa en el sitio se consigna en el siguiente Cuadro 5:

Cuadro 5: Levantamiento exterior Fraccionamiento cerrado

\begin{tabular}{|c|c|c|c|c|c|c|c|}
\hline \multicolumn{8}{|c|}{ Vialidades externas } \\
\hline \multicolumn{2}{|l|}{ Jerarquía } & \multicolumn{2}{|l|}{ Dimensiones } & \multicolumn{2}{|c|}{$\begin{array}{ll}\text { Tipo } & \text { de } \\
\text { pavimento } & \\
\end{array}$} & \multicolumn{2}{|l|}{ Calidad espacial } \\
\hline Primaria & 2 & $\begin{array}{lr}\text { Ancho } & \text { de } \\
\text { toda } & \text { la } \\
\text { sección } & \end{array}$ & $\begin{array}{l}12.30 \\
\mathrm{~m} .\end{array}$ & Terracería & & $\begin{array}{l}\text { Estado de } \\
\text { Conservación } \\
\text { predominante }\end{array}$ & Regular \\
\hline Distribución & 3 & $\begin{array}{l}\text { Ancho de } \\
\text { la acera }\end{array}$ & $8.60 \mathrm{~m}$. & Empedrado & & $\begin{array}{l}\text { Arborización } \\
\text { para el peatón }\end{array}$ & Malo \\
\hline Local & 0 & \multirow{3}{*}{$\begin{array}{l}\text { Ancho de } \\
\text { la } \\
\text { banqueta }\end{array}$} & \multirow{3}{*}{$1.80 \mathrm{~m}}$. & Asfalto & & \multirow{3}{*}{$\begin{array}{l}\text { Alumbrado } \\
\text { público }\end{array}$} & \multirow{3}{*}{ Regular } \\
\hline Peatona & & & & Concreto & $Q_{1}$ & & \\
\hline Otra & & & & Adoquín & & & \\
\hline
\end{tabular}

Los elementos observados permites concluir que la zona es de vivienda media a media-alta, con pavimentos de concreto. Al exterior la conservación en general es regular con pocos árboles y alumbrado público en regular condición; mientras que al interior la conservación es buena, con más arborización y buena iluminación pública. Se complementa la observación directa con los Cuadros 6 y 7.

Cuadro 6: Levantamiento exterior Fraccionamiento cerrado 


\begin{tabular}{|c|c|c|c|c|c|c|}
\hline \multicolumn{7}{|c|}{ Características externas y de muros perimetrales } \\
\hline $\begin{array}{l}\text { El material permite ver al } \\
\text { interior }\end{array}$ & \multicolumn{5}{|l|}{ Si } & No \\
\hline Calidad visual & Bueno & \multicolumn{4}{|l|}{ Regular } & Malo \\
\hline \multirow{2}{*}{ Pintura en fachada } & \multicolumn{2}{|l|}{$\mathrm{Si}$} & \multirow{2}{*}{$\begin{array}{l}\text { ¿En qué } \\
\text { estado? }\end{array}$} & \multirow{2}{*}{ Bueno } & \multirow{2}{*}{ Regular } & \multirow{2}{*}{ Malo } \\
\hline & \multicolumn{2}{|l|}{ No } & & & & \\
\hline Existencia graffiti & \multicolumn{2}{|l|}{ Mucho } & \multicolumn{2}{|l|}{ Poco } & Regular & Nada \\
\hline Existencia de publicidad & \multicolumn{2}{|l|}{ Mucho } & Poco & \multicolumn{2}{|c|}{ Regular } & Nada \\
\hline Remetimientos & \multicolumn{3}{|l|}{$\mathrm{Si}$} & \multicolumn{2}{|c|}{ No } & \\
\hline Limpieza & Buena & \multicolumn{4}{|l|}{ Regular } & Mala \\
\hline
\end{tabular}

Se aprecia en esta información una calidad en general entre buena y regular, al exterior del fraccionamiento, y que como se mencionó anteriormente, genera espacios residuales el cerramiento de calles que son aprovechados por los habitantes vecinos del fraccionamiento.

\section{Cuadro 7: Levantamiento exterior Fraccionamiento cerrado}

\begin{tabular}{|c|c|c|c|c|c|c|c|}
\hline \multicolumn{8}{|c|}{ Características externas y de muros perimetrales } \\
\hline \multirow{2}{*}{\multicolumn{3}{|c|}{$\begin{array}{l}\text { Mobiliario urbano, áreas de } \\
\text { descanso o socialización }\end{array}$}} & $\mathrm{Si}$ & \multirow{2}{*}{ Tipo } & \multirow{2}{*}{\multicolumn{3}{|c|}{ Cancha básquetbol }} \\
\hline & & & No & & & & \\
\hline $\begin{array}{l}\text { Dispositivos de } \\
\text { seguridad }\end{array}$ & \multicolumn{2}{|c|}{ muros } & cámaras & policía & casetas & rejas & otros \\
\hline \multirow{2}{*}{$\begin{array}{l}\text { Obstrucciones } \\
\text { peatonales, } \\
\text { visuales } \\
\text { motrices }\end{array}$} & $\mathrm{Si}$ & \multirow{2}{*}{ Тіро } & Basura & \multicolumn{2}{|c|}{ Postes } & Árboles & $\begin{array}{l}\text { Puestos } \\
\text { Permanentes }\end{array}$ \\
\hline & No & & Publicidad & \multicolumn{2}{|c|}{$\begin{array}{l}\text { Materiales } \\
\text { construcción }\end{array}$} & Otros & \\
\hline
\end{tabular}

También se refleja parte de las preocupaciones de los residentes del coto, de la falta (desde su perspectiva) de dispositivos de seguridad como cámaras y rejas 
electrificadas. No se apreciaron obstrucciones de ningún tipo en las calles aledañas. En el segundo caso de estudio, las privadas cerradas sobre avenidas principales (ver imágenes 7 a 10) Camelinas y Solidaridad, los resultados fueron muy similares a lo obtenido en el fraccionamiento cerrado.

Los vecinos que han cerrado estas privadas con rejas, encontraron al principio resistencia por parte de aquellas personas que tenían negocios, y que el acceso controlado podría afectar el paso de posibles clientes. Sin embargo, al aumentar en la zona la inseguridad por las razones antes expuestas, acabaron por ceder y apoyaron estos procesos.

Figura 7: Avenida Solidaridad esquina con Licenciado Eduardo Villaseñor Solórzano, pertenece al AGEB 1605300010594

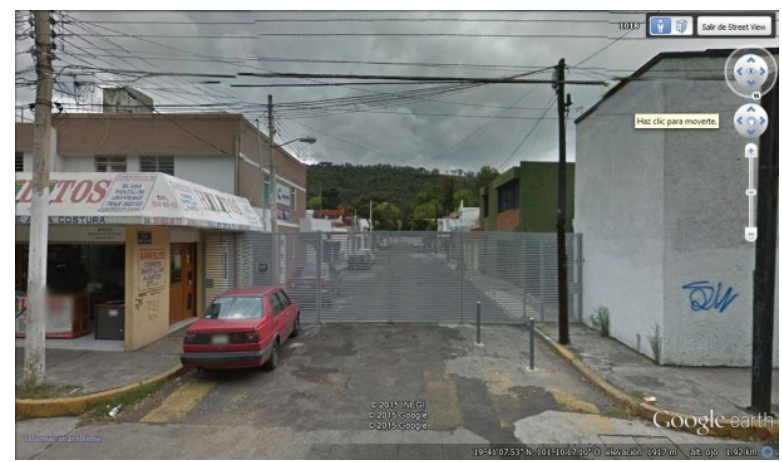

Fuente: Google Street [10/10/2015]

Figura 8: Avenida Solidaridad esquina con Maestro Alfonso Vega Núñez, Pertenece Al AGEB 1605300010594

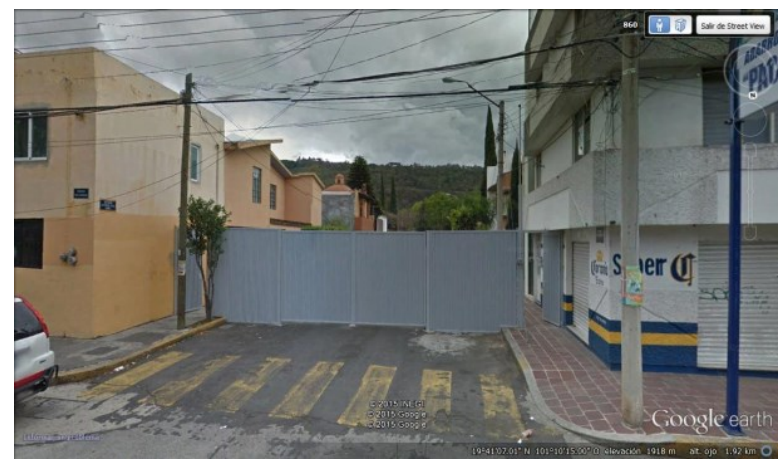

Fuente: Google Street [10/10/2015] 
Figura 9: Avenida Camelinas esquina con Doctor Manuel Martínez Báez, pertenece Al AGEB 1605300010594

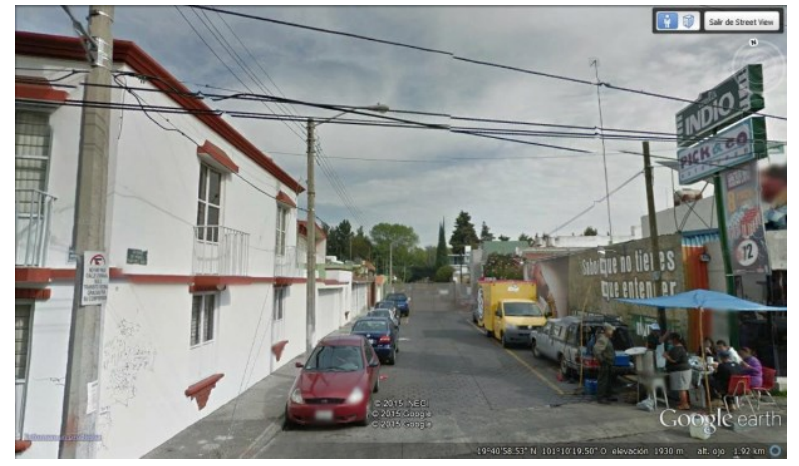

Fuente: Google Street [10/10/2015]

En la Figura 9 en particular, se observa que la reja fue colocada muy adentro de la calle privada, debido a que los comercios ubicados en las cercanías de la Avenida Camelinas requieren del ingreso de vehículos, en específico el Pick \& Go, tienda de conveniencia con servicio al interior del vehículo. Por ello, fueron los habitantes de las viviendas más cercanas al parque quienes colocaron la reja con control remoto para tener acceso controlado a pocas residencias.

La información que aquí se presenta para el segundo caso de estudio, es el referente a los tres primeros cuadros de caracterización de la población, percepción e imaginarios del miedo, correspondientes a lo descrito para el primer caso de estudio (ver Cuadros 8, 9 y 10).

Cuadro 8: Caracterización de la población residente en las privadas
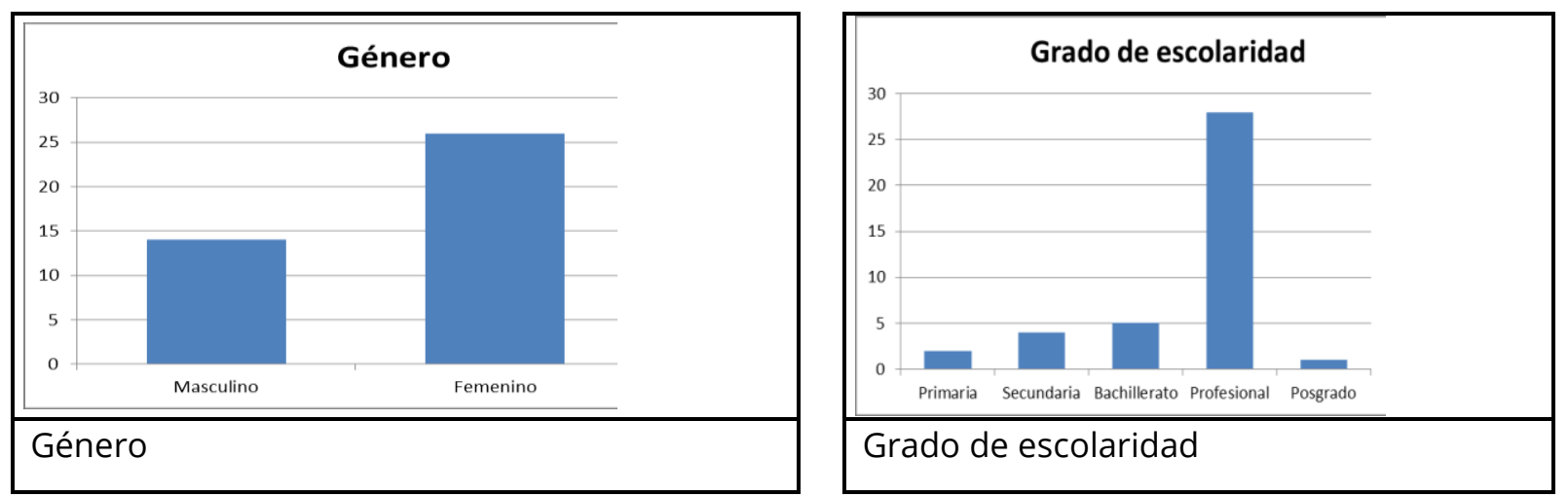

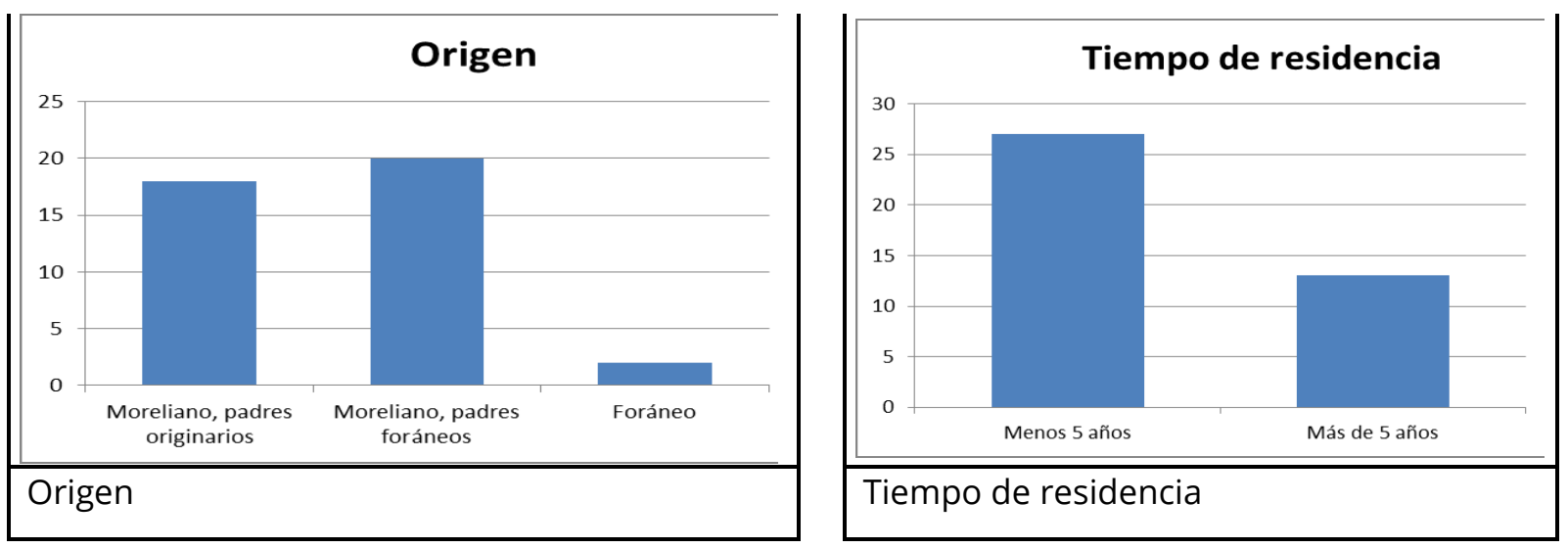

En este caso (ver Cuadro 8), se apreció un mayor equilibrio entre personas de ambos sexos que respondieron a las encuestas, y un mayor grado de personas con estudios profesionales, lo cual puede interpretarse como una zona de clase media alta trabajadora. Al profundizar las entrevistas, se confirma esta suposición, en que en la mayoría de las familias que residen en estas privadas trabajan tanto la madre como el padre, y tienen en general 2 a 3 hijos. La mayoría son morelianos, con un 25\% de personas de origen foráneo. También destaca que a diferencia del fraccionamiento cerrado, que tiene dieciséis años de haberse autosegregado, el 75\% de los residentes actuales de las privadas han vivido en ellas por menos de cinco años, coincidiendo con el inicio de la colocación de rejas posterior al año 2011.

Cuadro 9: Percepción de la población residente en las privadas
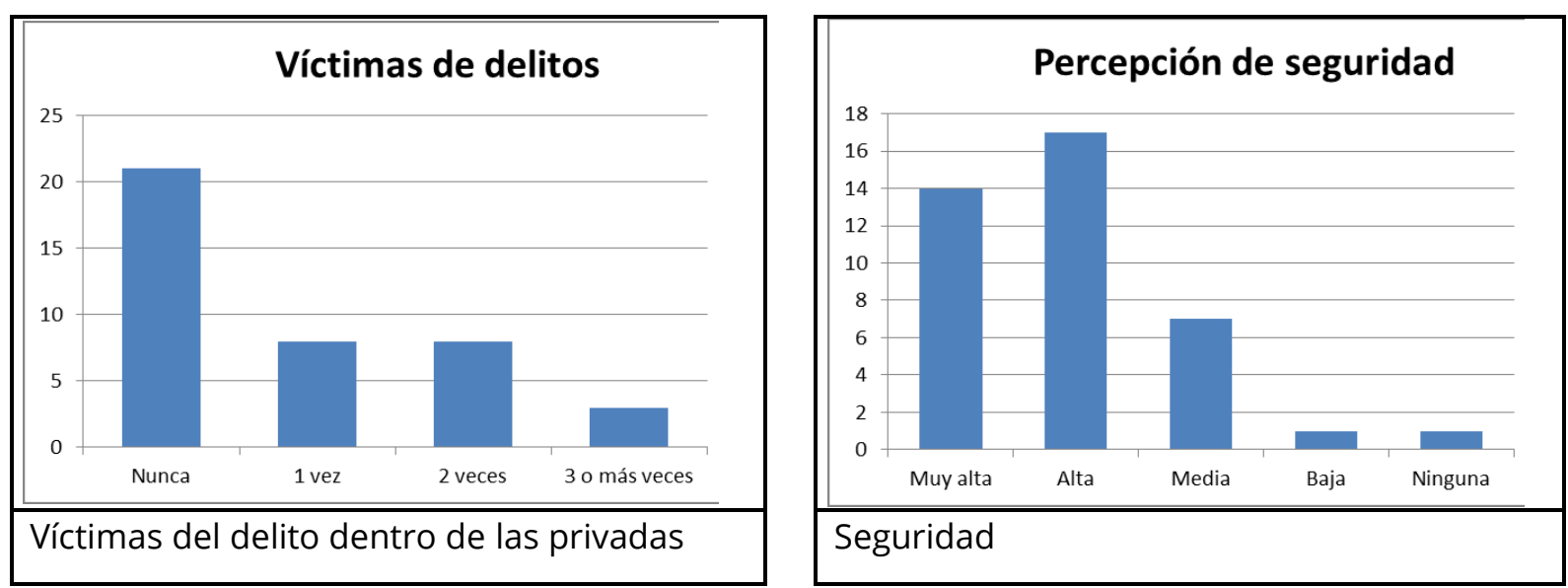

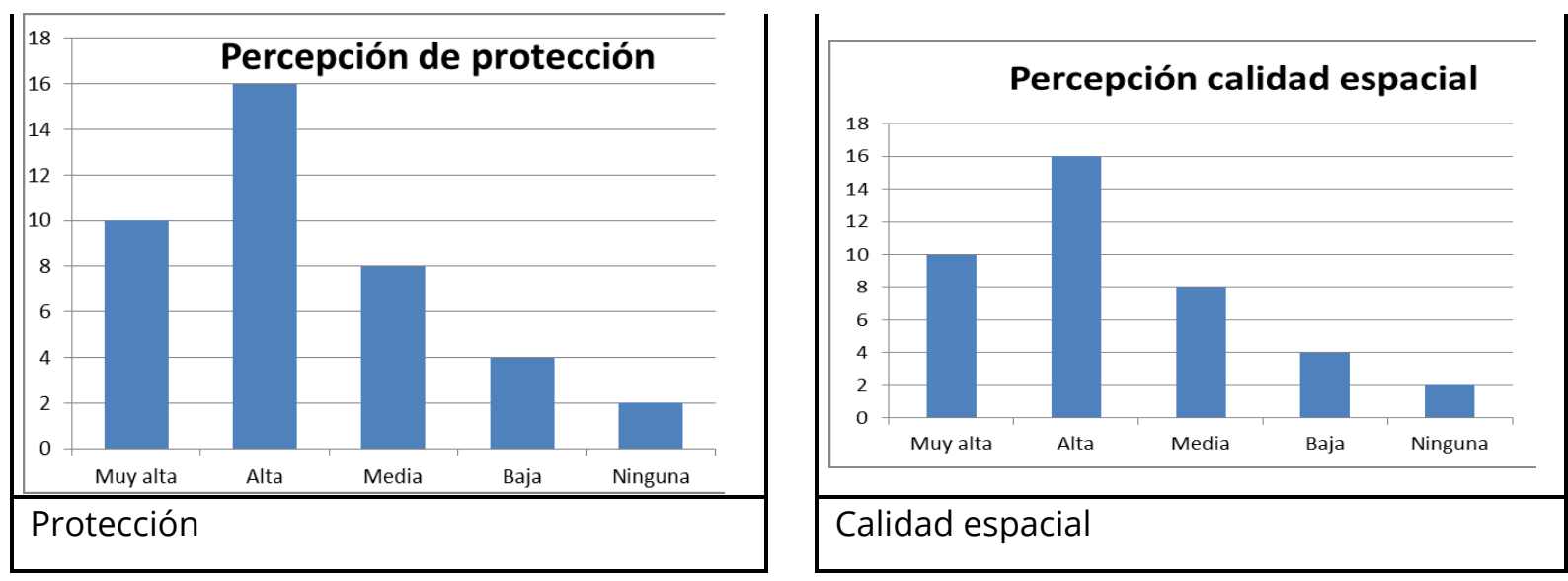

En el Cuadro 9, y de manera similar al fraccionamiento analizado de manera previa, el $25 \%$ de los residentes han sido objeto de delitos (robo a casa habitación en específico) dentro de las privadas, aunque sigue siendo mayoría (50\%) las personas que no han sido víctimas de robos. Su percepción de seguridad en las privadas es mayormente alta y muy alta, con un $25 \%$ de residentes que la consideran baja, coincidiendo con los que en el rubro anterior han sufrido robos en sus viviendas. En cuanto a la sensación de protección generada por la instalación de rejas, el 50\% la considera muy alta, y el resto entre media y baja, lo cual concuerda con las personas que si han sido víctimas de delito dentro de estos espacios cerrados. Complementando esta percepción, la gran mayoría considera que la calidad del espacio creado por la autosegregación de sus calles es muy alta.

Cuadro 10: Percepción de los imaginarios del miedo de la población residente las privadas
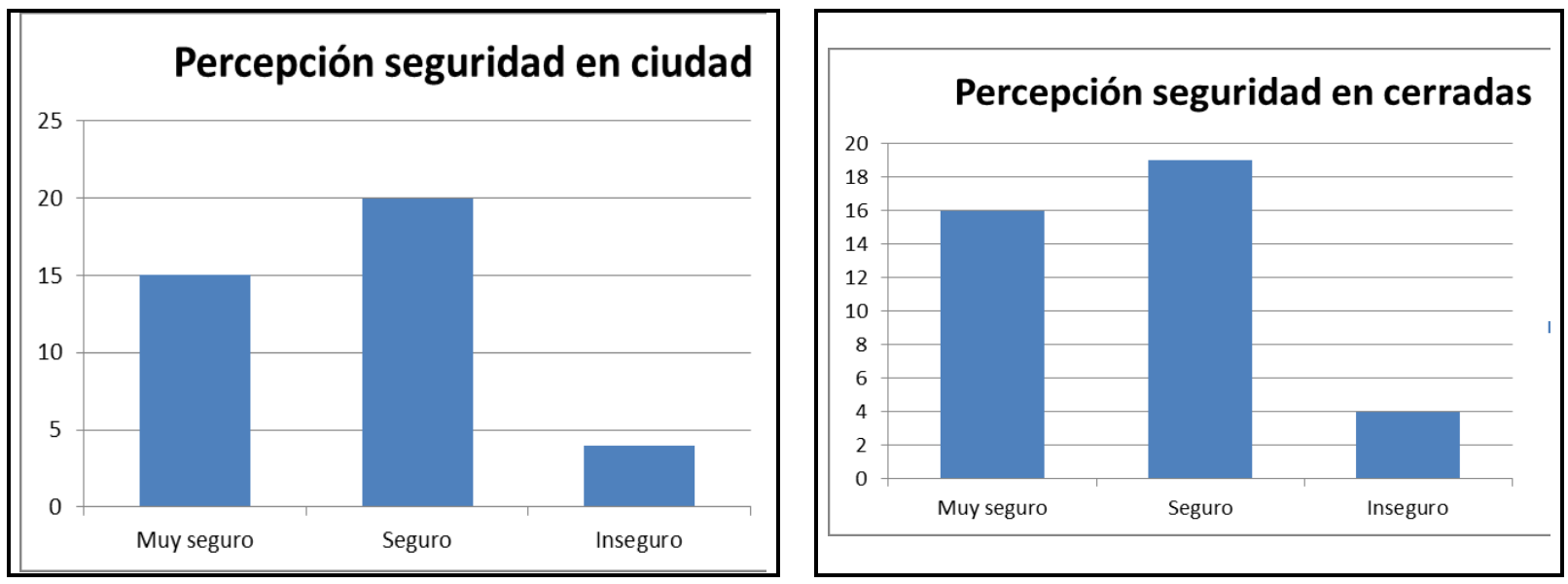


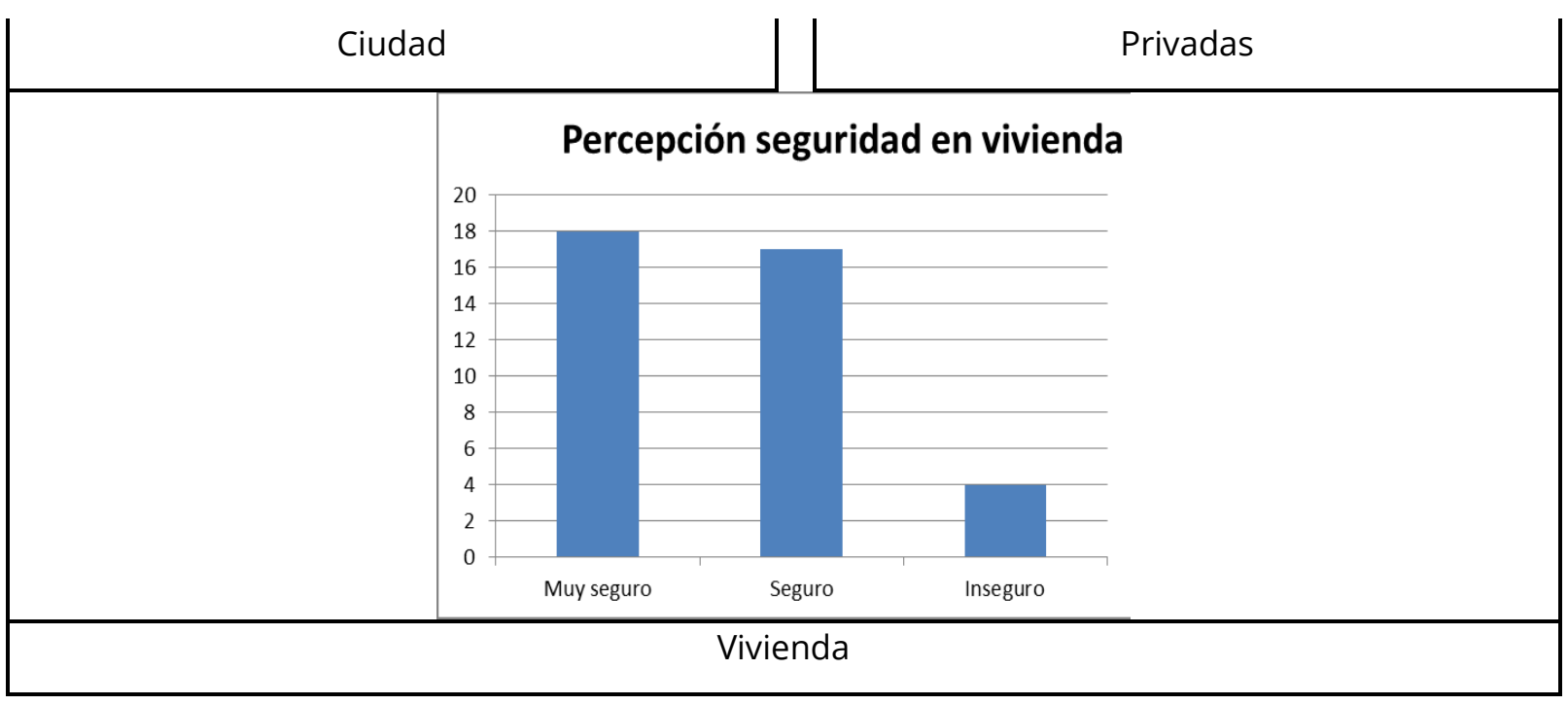

En el Cuadro 10 sobre percepción de los imaginarios del miedo, las respuestas difieren más de lo obtenido en el estudio de caso anterior (fraccionamiento autocerrado), pues se aprecia una constante en cuanto a la inseguridad prevaleciente en Morelia, en sus calles cerradas y en sus viviendas. Esto nos lleva a suponer que a diferencia del fraccionamiento cerrado, la mayoría de los residentes encuestados se siente muy seguro en los tres aspectos. Al profundizar en las entrevistas, no se manifestó un deseo por aumentar los dispositivos de seguridad. En el caso de las privadas, no se aplicaron los Cuadros 4, 56 y 7, debido precisamente a que son calles con rejas, sin muros exteriores ni calles interiores.

\section{CONCLUSIONES}

Retomando lo planteado en un inicio, la crisis nacional ha desatado una ola de inseguridad que ha generado nuevos imaginarios del miedo en la mayoría de los mexicanos, y en especial, a los habitantes del estado de Michoacán. Este aumento en la inseguridad y el crecimiento exponencial del delito, sobre todo en zonas urbanas, ha generado nuevos procesos urbanos complejos, reflejo de las sociedades que las habitan, y las transforman, al ritmo que las dinámicas sociales crean.

Como menciona López a principios del siglo XXI ciertas tendencias de cambio y reestructuración urbana se hicieron cada vez más patentes, "se ha recurrido a los 
discursos del miedo y a las huellas que éste deja en la ciudad y su paisaje, a modo de muros, rejas, plumas y demás elementos que separan a sus habitantes" (2005:21).

En nuestros casos de estudio, se pudo comprobar que ambos procesos de autosegregación fueron resultado de la percepción de inseguridad, y del miedo generado por el incremento de los delitos, sobre todo robo a casa habitación, que se dio en la zona oriente de Morelia. A diferencia de lo analizado en los ejemplos análogos, en que son los promotores inmobiliarios los que "venden" seguridad dentro de fraccionamientos cerrados creados así desde su origen, en los estudios de caso de la presente investigación, fueron los habitantes quienes buscaron crearse esa seguridad con recursos propios.

Sin embargo, es de resaltar la diferencia de percepción del miedo entre ambos casos: en las privadas se obtuvo resultados de menor percepción de inseguridad en cuanto a que no consideraron necesario tener más dispositivos de seguridad, mientras que en el fraccionamiento autocerrado se sintieron faltos de estos.

Ambos casos de estudio tuvieron acciones de autosegregación que tuvieron un impacto en las dinámicas urbanas, sobre todo el fraccionamiento, ya que cerró el paso a la libre circulación para cruzar esta zona, generando desplazamientos más largos para llegar al otro lado de manera exterior al coto, aunque a diferencia de los fraccionamientos cerrados desde su diseño, no hay largos muros cerrados al exterior, ya que las colindancias con otras viviendas son los límites del mismo.

La autosegregación, como se pudo ver en los cuatro ejemplos análogos revisados, implica cambios en las dinámicas espaciales, y también en las prácticas sociales, al evitar la interacción de los "de adentro" con los "de afuera". La fragmentación de las ciudades ha aumentado, de la mano con los imaginarios del miedo que son transmitidos cada día en los medios de comunicación masivos, aumentando la percepción de la inseguridad y creando más miedo, en una espiral ascendente que afecta directamente a las estructuras urbanas.

\section{AGRADECIMIENTOS}


Este trabajo de investigación es financiado por la Coordinación de la Investigación Científica de la Universidad Michoacana de San Nicolás de Hidalgo, y apoyado por el programa de Servicio Social de la Facultad de Arquitectura, con los alumnos de $8^{\circ}$ semestre Alejandra Romero, Cristina Gutiérrez y Antonio Quesada.

\section{REFERENCIAS}

BARTOLINI, S. Manifesto per la felicitá. Come pasarse dalla societá del ben-avere a quella del ben-essere, Roma, Donzelli, 2010.

CASTRO, JOSÉ ANTONIO. "Cierres de calles continúan por inseguridad en Morelia, su aceptación no es unánime" en Cambio de Michoacán, 7 de octubre de 2015, consultado en http://www.cambiodemichoacan.com.mx/imprime26609 [15/10/2015].

DE LA TORRE, MARÍA INÉS. “Demanda de seguridad en las metrópolis emergentes" en MARINA DE LA TORRE, DAVID NAVARRETE, MIGUEL ÁNGEL GARCÍA, MAURICIO VELASCO (coords.) Desafíos urbanos; Coloquio IV de investigación en arquitectura, México, Miguel Ángel Porrúa/Universidad de Guanajuato, 2014.

GALAVIZ, MARÍA ISABEL Y VALLADARES ANGUIANO, REYNA. "Los fraccionamientos cerrados residenciales de clase alta, una de las realidades de inseguridad urbana subjetiva. Caso Colima-Villa de Álvarez" en REYNA VALLADARES ANGUIANO (coord.) Diálogos entre ciudad, medio ambiente y patrimonio, Colima, Universidad de Colima, 2014.

HERNÁNDEZ SAMPIERI, ROBERTO, et. al. Metodología de la Investigación, México, McGraw-Hill, 2008.

INSTITUTO CIUDADANO DE ESTUDIOS SOBRE INSEGURIDAD (ICESI) <http://www.icesi.org.mx/estadisticas/index.asp> fecha de consulta 5/10/2015.

INSTITUTO NACIONAL DE ESTADÍSTICA, GEOGRAFÍA E INFORMÁTICA (INEGI) Encuesta Nacional de Victimización y Percepción sobre Seguridad Pública 2015, http://www.inegi.org.mx/est/contenidos/proyectos/encuestas/hogares/regulares/envi pe/envipe2015/default.aspx fecha de consulta 24/10/2015.

JUÁREZ MARTÍNEZ, MA. LILIANA “Segregación urbana y sus implicaciones en las ciudades. Una aproximación teórica" en Palapa, Julio-diciembre 2006, Colima, Universidad de Colima, 2006.

LARA NAVARRETE, ILEANA BEATRIZ. "Seguridad, estatus y permisividad administrativa. Motivos de un modelo urbano insustentable en Mérida, Yucatán" en ELOY MÉNDEZ, 
ISABEL RODRÍGUEZ Y JESÚS ENRÍQUEZ (coords.). Arquitecturas alegóricas y urbanismos defensivos, México, El Colegio de Sonora/Universidad de Sonora, 2010.

LÓPEZ LEVI, LILIANA. "Fortificaciones habitacionales en México. De la violencia dominante a la violencia dominadora" en Argumentos, estudios críticos de la sociedad, Año 24, número 66, mayo-agosto 2001, México, UAM Xochimilco, 2011.

LÓPEZ LEVI, LILIANA Y RODRÍGUEZ CHUMILLAS ISABEL. Miedo y consumo: el encerramiento habitacional en México y Madrid, México, UAM Xochimilco/Universidad Autónoma de Madrid, 2005.

MEJÍA MORALES, NORMA Y LAMY ARCHAMBAULT, BRIGITTE. "Participación social y gestión urbana: ¿evolución conceptual?" en JORGE CARLOS PARGA Y ALEJANDRO ACOSTA (coords.), La cultura científica en la arquitectura: patrimonio, ciudad y medio ambiente, México, Universidad Autónoma de Aguascalientes, 2014.

ROSAS MOLINA, JESÚS MARTÍN. “El asalto al espacio público. Fraccionamientos Cerrados en Nogales, Sonora" en ELOY MÉNDEZ, ISABEL RODRÍGUEZ Y JESÚS ENRÍQUEZ (coords.) Arquitecturas alegóricas y urbanismos defensivos, México, El Colegio de Sonora/Universidad de Sonora, 2010. 